\title{
The Expression of Cross-cultural Values in American Animated Films from the Perspective of Communication
}

\author{
Pei $\operatorname{Yan}^{1, *}$ \\ ${ }^{1}$ Department of New Media Art, National Academy of Chinese Theatre Arts, Beijing 100073, China \\ *Corresponding author. Email: peiyanhenniu@163.com
}

\begin{abstract}
Animation refers to the comprehensive visual art with images as the core medium and carrier. The essential attributes determine that its core should originate from the national cultural characteristics of the region. Contemporary American cartoons have a huge influence on global national culture. From the perspective of communication, the aesthetic awareness of visual art and the outward communication of national culture and history have developed into an effective carrier of cross-cultural communication. This article mainly analyses the cultural values of American animated films from many aspects such as American culture and value output through the research and analysis of American cartoons, and discusses the development of cross-regional and cross-cultural communication.
\end{abstract}

Keywords: American animated film, Cross-culture, Values.

\section{INTRODUCTION}

Animated film is a kind of media tool that transcends ethnic culture and has the output of cultural values. It carries a new and more complex aesthetic value. Looking at the animated film worldwide, American animated film is regarded as the vane of international animated film. In the 1990s, DreamWorks, Pixar, Disney and other companies launched brand-new TV and animated films, which set off a new wave of American animated films. Animated films with distinctive styles freely run through the fields of culture, politics and art, creating wonderful, magnificent and unspeakable dream worlds, and realizing the wide spread of cross-culture. The universality of culture and the transformation of culture break through the barriers of cultural dimensions and make American culture shine in foreign cultural groups.

\section{AMERICAN VALUES IN CROSS- CULTURAL COMMUNICATION}

Values are the idea collection of ideology and culture worldwide, the cognition and emotion between different cultures formed in practice, and the deep-seated idea with stable and leading role. The culture that American animated films want to show is not simply entertainment. It is more a reflection of American political and cultural values. It is a reorganization and interpretation of the ideological and spiritual space of the whole American society. Through aesthetic deconstruction in different periods, the vivid images of liberalism, humanitarianism and individualism are constructed. On this basis, the value orientation with American characteristics is formed, which is easy to arouse the soul resonance of the audience and be interpreted and accepted by the audience of different cultures. This process is closely related to the universality of cultural communication and the transformation of different cultures.

\subsection{The Universality of Core Values}

Individualism is one of the core values of the United States. It is the self-realization of universal value and liberalism. Free and equal competition is the fundamental guarantee and a fundamental way to realize American self-worth. [1] In the United States, people respect others who rely on their ability and courage to succeed. For example, in the 
animated film "Zootopia", Judy is a typical "fool succeeds". Under the "political correctness" of Zootopia, Judy is forced to realize his "ideal" — to be a policeman, to solve a pending case and to become a "fish out of water" through his own struggle. That is, Judy finds his own belonging in the new "world". Different people have different views. Judy's inspirational story shows a typical reality in the current global society - the dream complex of small potato. The whole film is like a mirror. It not only depicts dreams and growth, but also spreads American cultural values all over the world. In the process of experiencing and recognizing values, audiences are unconsciously affected by American culture with the help of the universality of localized symbols. "Anyone can be anything" is the refinement of the core values of American culture. The universal values of the film make the global audience immersed in the thoughts and culture contained in "Zootopia", while the "compound" ideology adapts to the cultural characteristics and aesthetic orientation of foreign audiences, obtaining the perception and recognition of the global audience, and achieving the crosscultural recessive communication of American core values.

\subsection{The Transformation of Value Culture to Different Culture}

Cross-regional cultural communication is a kind of information transmission activity between social members under different regional cultural background. [2] It mainly involves the diffusion of various cultural factors in the world and regions, as well as their influence on different regional cultures and countries. When one culture and another culture achieve the perfect fusion of emotion, the cognition and understanding of culture and similarities and differences in the process of communication, the communication differences between human and nature caused by cultural barriers have been eliminated. The process of one culture being absorbed and transformed by another culture is actually the change and transformation of one culture. Finally, a hybrid local culture and foreign culture is formed, with certain values.

"Zootopia" is a typical American animated film that absorbs cultural elements from different countries and makes cultural transformation. Adhering to Disney's consistent style, "Zootopia" organically integrates landscape city and animal elements, presenting a wonderful and illusory animal story, which is full of global cultural symbols. In order to make the film conform to the traditional culture of the country where the film is performed, each anchor in the film has his own image according to the country where the film is performed. In France and the United States, the anchor is a moose; in the Australia, the anchor is a koala; in Japan, the anchor is a Japanese koala; and in China, the anchor is a panda. When this picture full of Chinese images is presented to the Chinese audience, the Chinese elements only exist as a symbol. At this time, the Chinese culture is only superficial, and the panda anchor does not reflect the connotation of Chinese culture either from the appearance or from the inside. Panda anchor's plump face, broad body and cute eyes are typical impressions of pandas from the Western perspective. Its independent and free personality is in the same line with American culture, but far from the introverted and low-key characteristics of Chinese tradition. This film skilfully transforms the classic Chinese image of panda into the expression carrier of American culture, realizing the infiltration and dissemination of American values to different cultures.

There are many successful examples in the movie "Zootopia" in which the symbolic elements of foreign plastic culture are directly used as a kind of plastic culture symbol to directly transform various cross-regional cultural elements. For example, the exotic-shaped cultural elements of Saint Basil's Cathedral are directly applied to the Glacier Town where human beings are dominated by African polar wildlife. In this film, the largescale Russian column-shaped architecture is adopted; the Sahara square in the film is generally considered to be the comprehensive effect of Dubai, Las Vegas and Palm Springs in New York; and the interior garden of the railway station in the film mainly copies the Madrid central subway station, etc. These comprehensive cultural elements attract the global audience through the ingenious design and symbol transformation, realizing the crosscultural integration of American values, culture and aesthetic consciousness.

\section{THE INTEGRATION OF AMERICAN VALUES IN CROSS- CULTURAL COMMUNICATION}

Cultural values are specific values formed in the national core culture with the development of society. It is the hidden culture in the value system. It organically integrates the values of the people of all countries into a cultural system. 


\subsection{The Value Integration of Context Cultures}

Cross-cultural communication is based on different context cultures. High context culture emphasizes the relevance of meaning to context, while low context culture attaches importance to the established meaning and value of context cultural symbol itself. The symbol of context culture is based on cultural background and is the precipitation and accumulation of national culture. It changes with the change of society. The communication symbol of context cultural value is not exactly the same in different times.

Most of the information in the transmission of high context culture exists in a high material context, and the transmission of low context culture comes from the material context. [3] Therefore, the value of context culture presented by animated films is always closely related to culture and social life style, whether it is content or form. In the transmission of context culture, various cultural and social symbols in "Zootopia" are unfolded in the way of image, thus realizing an image expression without covering up. This kind of image-oriented context culture expression is integrated and accepted by different cultures around the world. For example, the objects in the film are highly personified, forming a strong sense of substitution. Nike and Starbucks ingeniously appear in "Zootopia". However, Nick, DKNY, New York Times, Burberry, Prada, Uber, Google and other imagery cultural symbols make the audience explore the cities in the film from a new perspective. The familiar symbols around the world are spread in the unrestrained and vigorous style. At the same time, they are highly consistent with the cultural context that the film conveys, and its values of "spiritual individuality" are highly integrated.

In "Zootopia", the exaggeration and joking context theme suggests the social phenomena in the real society. For example, carnivores represent the minority elite of the society, and most herbivores represent the mainstream society. Inequality between men and women, urban and rural differences, arrogance and prejudice are performed in the "social stage". Judy is cheerful and kindhearted, but she is not popular. A bed, a table and a noisy neighbour are tailored living situations for her. Funny plots and details further depict her heroismoriented cultural label. Nick, the chattering fox, always provides a variety of laughs to the audience. The hamster with uniform action is a subtle joke on modern people. All these obscure, indirect and recreational contextual ways show the behaviour and values of modern people in different countries. Therefore, the spread and integration of cultural values in context is a direct manifestation of the common emotional values. [4]

\subsection{The Value Integration of Foreign Subjects}

Each nation has its own unique culture, which determines its thought and behaviour pattern. Different cultures are distinguished from other cultures by their internal special goals. Therefore, different societies have different cultural patterns. When the national culture moves towards the world, it is bound to merge and form a new culture, which is a continuous process. [5] The spread of culture makes different cultures contact with each other, learn from each other, resulting in cultural integration and the formation of new cultural values. In this context, the multi-cultural creation themes among different nationalities will win universal recognition.

The choice of creative theme is the subjective expression of the creator's values and aesthetic intention. When the creative theme is deconstructed into universal values, the cultural boundary has become blurred, and it is no longer a single culture, but a part of global culture.

"Zootopia" is a cartoon with American traditional culture as the main background. The creator skillfully grafts aesthetic consciousness and values into "Zootopia" with a story that does not violate any folk customs and ethnic taboos, and spreads American culture to the whole world. Judy and Nick work together to solve the case, the majestic mayor (the lion) and vice mayor (the sheep) work together, and the irascible director (Berg) and the cheetah officer work together. All these constitute an ideal "American Utopia". In the "story", pure habitat, coupled with the moral ideal beyond the realm of reality, evokes the childlike interest of audiences of different societies, cultures and ages. The combination of extraterritorial culture on the screen, the most popular culture around the world, and so on, has wrapped the coat of extraterritorial culture on the American cultural values, making it "one", forming a story with a sense of the times, exploring human nature and values, and realizing the global integration of American cultural values under the surface of enthusiasm and noise. 
The narrative style, role modeling and image style of "Zootopia" deconstruct the foreign cultural symbols with the method of "animalization",[6] and replace the "foreign" culture with the narrative theme of specific values, achieving the communication to other countries. Although the culture in the film is no longer pure, the audiences keep close to it and unconsciously identify with the cultural values of the United States.

\section{CONCLUSION}

In the contemporary economic society with mass groups and mass consumption culture as the core and leading, American animation and movies perfectly combine their commercial, entertainment and ideological attributes. "Zootopia" is a kind of art and business product in the popular mass culture market. With the pursuit of commercial interests, the creators have to add a series of commercial and entertaining elements to meet the audience's interest and demand for cultural consumption and cater to the audience's aesthetic appreciation and interest. The commercial and entertainment elements of the film bring the audience to the thinking of real life and complex human nature, which arouse the audience's curiosity and interest. The audiences have the sense of identity and psychological resonance in cultural communication.

The success of "Zootopia" in cross-cultural communication in the world makes people realize that as a fashionable and diversified country, American cross-cultural animated film owes to its unique integrated art and culture, [7] and its connotation is always rooted in the rich art and cultural soil of the United States, reflecting the connotation and choice of American traditional culture. While, it absorbs the essence of art and culture from all over the world. In the eternal theme of "love and self-growth", the fairytale-like "American dream" is created to publicize its spirit and value orientation to audiences all over the world.

The communication of meaning needs carrier. Through the "American Dream" which everyone is infatuated with, "Zootopia" shows the spread of American cultural hegemony and bears the responsibility of expressing culture and ideology. As a product of American culture, American animated film is the carrier of American culture, reflecting all aspects of American culture. [8] It can not only reproduce the western world in the past, but also show the values and outlook on life of American culture at present. When the "dumping" of the two popular cultures, the United States, Europe, Japan and South Korea, increasingly blends, it is obvious that China lacks the ability to resist and confront the cultural giants. People with insight are worried. In this cultural era, how to capture and recapture the spiritual city of the Chinese people, especially the next generation, will be a tough battle as that at the same level of political and economic competition.

China's cultural connotation is broad, inclusive and important. It is necessary to inherit and perfect any culture. Therefore, it is suggested to absorb all the cream and culture that can be absorbed. [9] There is an old saying: "it is better to do than to envy and wish in vain." In the process of crossregional cultural communication, it is suggested to consider the following questions, such as how to fully learn from the practice and experience of American modern animation and film in the process of cross-regional cultural communication in China, how to adhere to the Chinese nationality in the animation and film, how to integrate China's excellent tradition and cultural elements into the artistic text and the international and modern artistic and cultural environment, how to attract the audience with excellent modern animation theme, how to show the "image" and "meaning" of Chinese art and culture. If the above problems are solved, Chinese animated film plays a unique advantage in its cross-cultural communication context.

\section{AUTHORS' CONTRIBUTIONS} Yan.

This paper is independently completed by Pei

\section{REFERENCES}

[1] Liu Yumei, Song Tiechen. Looking at the values of the American dream from "Ratatouille" [J], Film Literature, 2008 (17). (in Chinese)

[2] Li Rong. Analysis of the reasons for the successful cross-cultural dissemination of Miyazaki Hayao's animation [J], China Newspaper Industry, 2013 (2), 102. (in Chinese)

[3] Ge Yuqing. Dialogue with Virtual World: Animated Film and Intercultural Communication [M], Beijing, Communication University of China Press, 2011, 93. (in Chinese) 
[4] [Germany] Hegel. "Aesthetics" (Volume Two), Translated by Zhu Guangqian, The Commercial Press, 1979 Edition, p. 32. (in Chinese)

[5] Chen Taowen. Cultural Transformation: Disney and Globalization in the Legend of Mulan in China [A], Selected Papers on Communication Studies (III) [C], Nanjing: Nanjing Normal University Press, 2000. (in Chinese)

[6] Ge Jing. "Film and Television Animation Script Creation", Beijing: Ocean Press, p. 10 of the 1st edition, February 2005. (in Chinese)

[7] Chen Guoming. An Ran. Interpretation of key terms in cross-cultural communication [M]. Beijing: China Social Sciences Press. 2010. (in Chinese)

[8] Chen Taowen. Cultural Transformation: Disney and Globalization in the Legend of Mulan in China [A], Selected Papers on Communication Studies (III) [C], Nanjing: Nanjing Normal University Press, 2000. (in Chinese)

[9] Zhou Dengfu. "Introduction to Film Art Design", Beijing: China Film Publishing House, July 2, 2007. (in Chinese) 